\title{
Improving the Clinical Pharmacist Handover Process in the Intensive Care Unit with a Pharmacotherapy-Specific Tool: The I-HAPPY Study
}

\author{
Emma Attfield, Matthew P Swankhuizen, Nicole Bruchet, Richard Slavik, and Sean K Gorman
}

\begin{abstract}
Background: Pharmacists in the intensive care unit (ICU) provide pharmaceutical care to critically ill patients. Identification and resolution of drug therapy problems improves outcomes for these patients. To maintain continuity of care, pharmacotherapy plans should be transferred to a receiving pharmacist upon discharge of patients from the ICU. No previous studies have addressed the development or evaluation of a systematic, standardized clinical handover tool and process for pharmacists.

Objectives: To assess pharmacists' satisfaction with and utilization of a pharmacotherapy-specific handover tool and process.

Methods: Plan-do-study-act methodology was employed to develop a clinical handover tool and process, which were implemented in a Canadian health authority. For evaluation of the tool and process, a multicentre, online survey questionnaire was distributed to 14 clinical pharmacists in the ICU and ward settings at 5 hospitals between February 15 and April 22, 2016.
\end{abstract}

Results: Thirteen of the pharmacists completed the survey. All 13 pharmacists (100\%) were satisfied with usability; 12 (92\%) were satisfied with training, organization, and accuracy of the process; and 11 (85\%) were satisfied with completeness and efficiency. Most pharmacists conducted 1 or 2 handovers per week, with each having a duration of $3-5 \mathrm{~min}$. Seven (54\%) of the respondents reported that they communicated handovers mostly or exclusively by telephone, and $6(46 \%)$ reported using mostly or exclusively face-to-face communication. However, $6(46 \%)$ reported a preference for face-to-face communication, and 3 (23\%) reported a preference for the telephone; the remaining 4 (31\%) had no preference for mode of communication.

Conclusions: Respondents were highly satisfied with the handover tool and process. ICU pharmacists appeared more satisfied with the training, organization, and completeness of handover, whereas ward pharmacists appeared more satisfied with the accuracy and efficiency of handover. Workload requirements were minimal, and face-to-face interaction, although slightly less well utilized than the telephone, was the preferred method of communication.

\section{RÉSUMÉ}

Contexte : Les pharmaciens exerçant dans les unités de soins intensifs (USI) prodiguent des soins pharmaceutiques aux patients gravement malades. Or, déceler et résoudre les problèmes pharmacothérapeutiques améliore les résultats cliniques pour ces patients. Afin de maintenir la continuité des soins, les plans pharmacothérapeutiques doivent être communiqués au moment du congé des patients de l'USI à un autre pharmacien qui prendra ensuite le relais. Aucune étude n'avait auparavant étudié la mise au point ou l'évaluation d'un outil et d'un processus normalisés de transfert des soins à être utilisés systématiquement par les pharmaciens.

Objectifs : Évaluer le taux de satisfaction des pharmaciens à l'égard d'un outil et d'un processus destinés au transfert des soins pharmacothérapeutiques et en analyser leur utilisation.

Méthodes : La méthodologie planifier-exécuter-étudier-agir a été employée pour mettre au point un outil et un processus de transfert clinique introduits dans une régie de santé canadienne. Afin d'évaluer l'outil et le processus, un sondage en ligne a été présenté à 14 pharmaciens cliniciens travaillant soit dans les USI soit dans d'autres services intrahospitaliers de 5 hôpitaux, entre le 15 février et le 22 avril 2016.

Résultats : Treize pharmaciens ont rempli le sondage. Les 13 (100\%) étaient satisfaits de la facilité d'emploi; 12 (92\%) étaient satisfaits de la formation, de l'organisation et de l'exactitude du processus; et 11 (85\%) étaient satisfaits du degré d'exhaustivité et de l'efficacité. La plupart des pharmaciens réalisaient 1 ou 2 transferts par semaine, chacun d'une durée de 3 à 5 minutes. Sept $(54 \%)$ répondants ont indiqué qu’ils communiquaient les transferts surtout ou seulement par téléphone et 6 (46\%) ont dit le faire surtout ou uniquement en personne. Or, 6 (46\%) ont indiqué une préférence pour la communication en personne et $3(23 \%)$ ont dit préférer la voie téléphonique. Les 4 (31\%) autres étaient indifférents au mode de communication utilisé.

Conclusions : Les répondants étaient grandement satisfaits de l'outil et du processus de transfert. Les pharmaciens exerçant dans les USI semblaient plus satisfaits de la formation, de l'organisation et du degré 
Key words: clinical handover, intensive care, pharmaceutical care, pharmacist

\section{Can J Hosp Pharm. 2018;71(2):111-8}

d'exhaustivité du transfert alors que les pharmaciens travaillant dans d'autres services intra-hospitaliers semblaient plus satisfaits de l'exactitude et de l'efficacité du transfert. La charge de travail était minimalement accrue et la communication en personne, bien qu'utilisée moins fréquemment que celle par téléphone, était le mode préféré.

Mots clés : transfert clinique, soins intensifs, soins pharmaceutiques, pharmacien

\section{INTRODUCTION}

$\mathrm{P}$ harmacists providing team-based, direct patient care to critically ill patients improve outcomes by implementing pharmaceutical care plans and resolving drug therapy problems (DTPs). ${ }^{1}$ For example, interventions by pharmacists in the intensive care unit (ICU) have been shown to reduce the incidence of ventilator-associated pneumonia, to prevent adverse drug reactions, and to shorten the duration of the hospital stay. ${ }^{1,2}$ ICU pharmacists intervene throughout a critically ill patient's journey from admission to transfer out of the ICU. However, it is often difficult to implement all aspects of a patient's pharmaceutical care plan in the ICU. Therefore, ICU pharmacists should hand over pertinent aspects of a patient's pharmaceutical care plan when the patient is transferred out of the ICU.

Clinical handover is defined as "the process of transferring primary authority and responsibility for providing clinical care to a patient from one departing caregiver to one oncoming caregiver" and is a communication-heavy event. ${ }^{3}$ Miscommunication when handing off responsibility for patients plays a role in an estimated $80 \%$ of serious preventable adverse events, and communication failure is among the top 3 most frequent causes of sentinel events, treatment delays, and transfer-related events. ${ }^{4,5}$

Standardized, structured handover tools and processes, such as the situation, background, assessment, recommendation (SBAR) approach and the subjective, objective, assessment, plan (SOAP) approach have been created to support and improve the quality of handover episodes. ${ }^{6}$ Standardization of handover, guided by forms or checklists, has been associated with reductions in adverse events, increases in perceived accuracy of transferred information, and faster finalization of ICU discharge documentation. ${ }^{6,7}$ However, a significant limitation of published handover tools is that they are too vague to fit the specific demands of clinical handover in different contexts. ${ }^{6,7}$

There is a paucity of published literature describing the effectiveness of pharmacist-specific handover tools and processes. One study evaluated the implementation of a pharmacist-initiated pharmaceutical handover tool for oncology and hematology patients requiring transfer to the ICU. ${ }^{6}$ Pharmacist handover of patients' medication-related information with guidance from a structured form significantly reduced medication errors and increased the on-time administration of medication therapies. ${ }^{6}$

A PubMed search from inception to March 1, 2017, revealed no studies addressing handover by ICU pharmacists. Before evaluating the effectiveness of a standardized pharmacist tool and process in improving information transfer, processes of care, and outcomes, it is essential to determine whether end-users are satisfied with key aspects of the tool and process. Low pharmacist satisfaction related to perceived usefulness and ease of use with a handover tool and process reduces the chance of adoption by pharmacists, rendering the tool and process ineffective in improving the quality of patient care. ${ }^{8}$ Therefore, the aim of this study was to assess pharmacists' satisfaction with a systematically developed clinical handover tool and process for patients transferred from the ICU to a hospital ward.

\section{METHODS}

\section{Design and Participants}

This online survey study was conducted in the pharmacy department of a Canadian health authority. This health authority encompasses 22 hospitals, 10 of which have clinical pharmacists on staff. Following receipt of approval from the institutional research ethics board, a general call for expressions of interest to participate in the study was made through the health authority's pharmacist e-mail forums for critical care, medicine, and surgery. Additionally, all ICU pharmacists belonging to these e-mail forums were contacted individually to ascertain their interest in participating. Thus, a convenience sampling method was used, and there was no target sample size.

Interested pharmacists were screened by the principal investigator (M.P.S.) to ensure they met the following inclusion criteria: clinical pharmacists dedicated to the provision of care to patients in an ICU of sufficient size (defined as 4 beds or more). All ICUs in the health authority had the capability to admit patients requiring invasive mechanical ventilator support and hemodynamic support. Clinical pharmacists who provided full-time coverage ( $7.5 \mathrm{~h} /$ day, Monday-Friday) on a medical or surgical ward and who received at least 1 patient transfer per week from an ICU with a participating full-time ICU pharmacist were 
also eligible to participate. Included pharmacists were involved in developing the checklist tool and handover process and were also part of the evaluation process (Figure 1). All participants provided written informed consent before participating in this study.

\section{Development of Checklist Tool and Handover Process}

The plan-do-study-act (PDSA) methodology ${ }^{9}$ was used in developing the checklist tool and handover process. Version 1 of the checklist tool and process was developed through coinvestigator consensus. The tool incorporated essential aspects of handover as described by the World Health Organization; these included using a standardized process, allowing time for questions, and limiting information to that which is necessary. ${ }^{10}$ Three key questions guided identification of components for the handover tool: Where do DTPs occur with respect to handover? Which pharmacist interventions increase patient adherence? What technical aspects of pharmaceutical care are pertinent to handover? To answer these questions and thus inform creation of the tool, a systematic review of the literature was performed by 2 of the investigators (E.A., M.P.S.) using PubMed (1950 to August 2015), Embase (1947 to August 2015), and Google Scholar.

Before PDSA cycle 1, a video presentation (developed by the author team) was used as a training module for participants; the video provided detailed information on the handover tool and process, and showed an example handover. When new versions of the tool and process were issued, a newsletter was used to inform participants about changes made. During cycle 1, participants implemented version 1 of the tool and process for 14 days. A teleconference focus group was then held (for which at least $50 \%$ of included pharmacists were required to be present) during which participant feedback was solicited using a semistructured interview guide (Appendix 1, available at https://www.cjhponline.ca/index.php/cjhp/issue/view/126/showToc). This feedback was used to inform adaptation and refinement of the tool and process leading to the creation of version 2 . The focus group was the only avenue for providing feedback; pharmacists who were unable to attend the teleconference were not given any other option for providing feedback. PDSA cycle 2 was analogous to cycle 1 (Figure 1). Then, the final version of the tool and process (Figure 2 and Figure 3, respectively) was implemented. The 2 focus group sessions used to refine the handover tool and process met quorum, with attendance by 9 pharmacists (64\%) for focus group 1 and 8 (57\%) pharmacists for focus group 2 .

\section{Evaluation of Checklist Tool and Handover Process}

After a 21-day implementation period for the final version of the checklist tool and handover process, pharmacist satisfaction and overall utilization of the tool and process were evaluated using

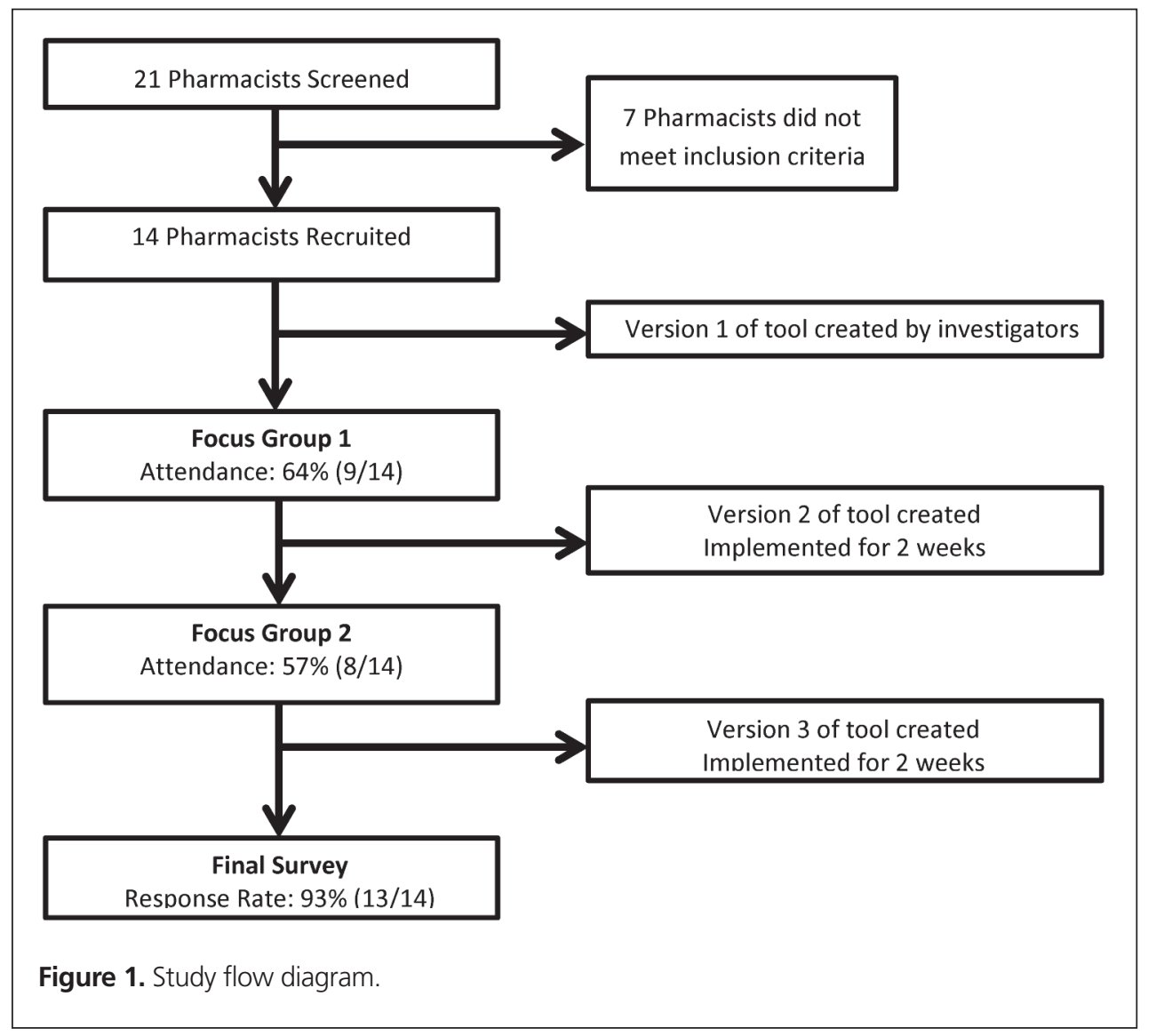




\author{
I Identification \\ $\square$ Full Name $\square$ Age $\square$ Gender \\ H History \\ $\square$ Date of admission to ICU \\ $\square$ Reason for admission to ICU \\ $\square$ Was reason for admission drug-related? \\ $\square$ Allergies \\ $\square$ Past Medical History \\ $\square$ Medications prior to admission \\ $\square$ Date of transfer or anticipated transfer out of ICU \\ A Actual and Potential DTP's \\ $\square$ List current medical conditions and current medications for each condition \\ $\square$ Actual and Potential DTP's \\ $\square$ Refer to "Common Issues in ICU Handover" \\ $\square$ Action plan to resolve DTP's \\ P Patient or Family Needs \\ $\square$ Education and counselling requirements during hospital stay or at discharge \\ $\square$ Patient preferences and beliefs with respect to drug therapy \\ P Pharmacist to Contact Healthcare Providers \\ $\square$ Need for community pharmacist contact \\ $\square$ Need for family physician contact \\ $Y$ Your Questions \\ $\square$ Answer all remaining questions posed by the receiving pharmacist
}

Figure 2. The I-HAPPY checklist tool for handover of a patient from intensive care unit pharmacist to ward pharmacist.
1. ICU and Ward Pharmacist Daily Review For Potential Handover The ICU and ward pharmacist will review their patient load daily for patients who meet criteria for handover.

Suggested duration: 5 minutes.

Patient Criteria:

- Transferring from ICU to medical/surgical ward

- Transferring today, tomorrow, or transferred yesterday

2. Contacting the Ward or ICU Pharmacist

Whomever first determines a patient transfer from ICU to ward occurred, either the ICU or ward pharmacist, will initiate contact with the other pharmacist (in person or by phone). Both pharmacists will agree on a mutually convenient meeting time to conduct handover.

\section{Handover Mode of Communication}

Verbal communication (in person or by phone). Written information (i.e. monitoring forms) may be provided to the receiving pharmacist if the ICU pharmacist and receiving pharmacist agree it is beneficial.

\section{Conducting Handover}

It is suggested that the ICU pharmacist, in preparation for handover, identifies all medication reconciliation issues (with reference back to admission BPMH) and DTP's based on their last encounter with the patient. It is suggested that the ICU and/or ward pharmacist, in preparation for handover, have knowledge of the most up-to-date medication list. In addition, pharmacists should obtain a copy of the "IHAPPY" tool for reference.

Handover will follow tool components in the set numbered order, from top to bottom. Efforts should be made to minimize the risk of distractions and interruptions in the surrounding environment while conducting handover.

\section{Documentation of Handover}

As per the Clinical Practice Standard for Health Record Documentation, interventions facilitated by handover may be documented in the patient chart by the ward pharmacist as per standard practice. These may include, but are not limited to:

- Transfer medication reconciliation

- IV to PO antibiotic stepdown

- Patient education/counselling

- Seamless care activities

Documentation may occur in the progress notes or care plan record depending on the nature of the intervention.

Figure 3. The I-HAPPY process for handover from intensive care unit pharmacist to ward pharmacist. an online survey administered through SurveyMonkey (https://www.surveymonkey.com/); the survey questions are available in Appendix 2 (at https://www.cjhp-online.ca/ index.php/cjhp/issue/view/126/showToc). To be eligible to complete the survey questionnaire, a pharmacist had to have conducted at least 1 handover during the final 21-day period. Six domains of satisfaction were evaluated: usability of the tool and process, training provided on the process and tool (learnability), efficiency of the handover process, completeness of the tool and process, accuracy of the tool and process, and organization of information transfer when using the tool and process. Respondents were asked to rate each domain on a 5-point Likert scale, from very dissatisfied (1) to very satisfied (5). Satisfaction with the tool or process was defined a priori as a rating of 4 or 5 on the 5-point Likert scale. Pharmacists' utilization of the handover tool and process with respect to workload and communication was evaluated using the same survey questionnaire. The workload parameters were the estimated time to conduct handover and the average number of handovers per week, as reported by survey respondents. The communication parameters were the communication method utilized and preferred. Results are reported for the entire group and for subgroups of ICU pharmacists and ward pharmacists. Additionally, data were collected for the following baseline characteristics: pharmacist coverage area (ICU or ward), years of clinical experience, and handover practices before this study. All results are reported with descriptive statistics for binary and ordinal data.

\section{RESULTS}

A total of 21 pharmacists were screened, of whom 14 were eligible for inclusion. However, 1 pharmacist did not complete 
the survey questionnaire, so the final sample consisted of 13 pharmacists: 4 (31\%) ICU pharmacists and 9 (69\%) ward pharmacists. Eleven $(85 \%)$ of the respondents had less than 5 years of experience in hospital pharmacy, $1(8 \%)$ pharmacist had 5-10 years of experience, and $1(8 \%)$ had more than 10 years of experience. Twelve (92\%) of the respondents reported that, before this study, they had occasionally participated in handover, and $1(8 \%)$ reported consistently participating in handover.

At least $85 \%$ of pharmacists were satisfied or very satisfied with the handover tool and process across all 6 satisfaction domains evaluated (Figure 4). Among the ICU pharmacists, all
4 were satisfied or very satisfied with usability, training, organization of information, and completeness of information in the tool and process, $3(75 \%)$ were satisfied or very satisfied with the accuracy of the tool and process, and $2(50 \%)$ were satisfied or very satisfied with the efficiency of the tool and process (Figure 5). At least $78 \%$ of the ward pharmacists were satisfied or very satisfied with the handover tool and process across all 6 satisfaction domains (Figure 6).

Reported workload outcomes are presented in Table 1. Eight (62\%) of the 13 pharmacists reported that workload associated with handover most frequently entailed a 3- to 5-min discussion,

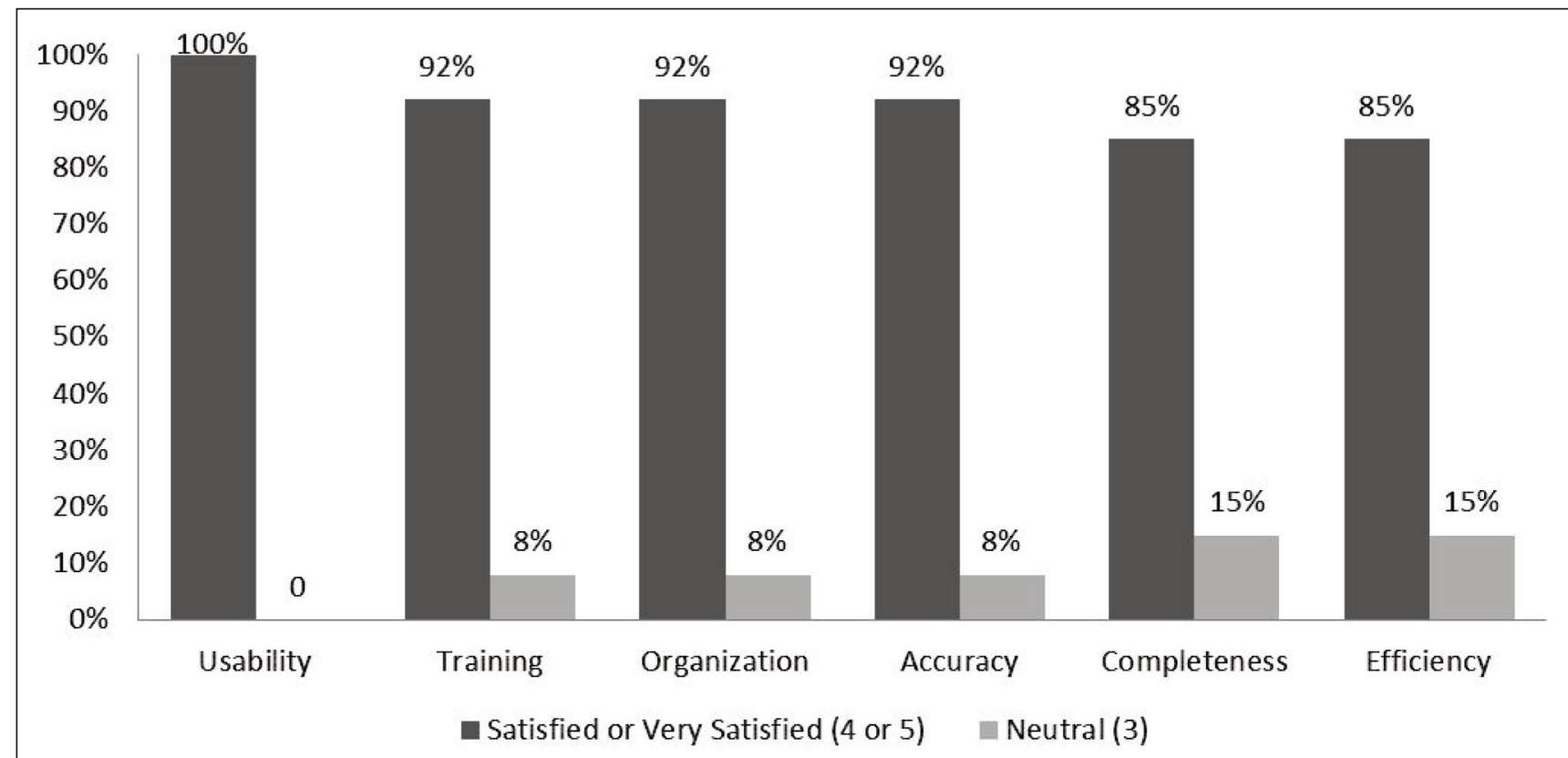

Figure 4. Overall satisfaction levels with various aspects of the handover process and tool ( $n=13$ respondents).

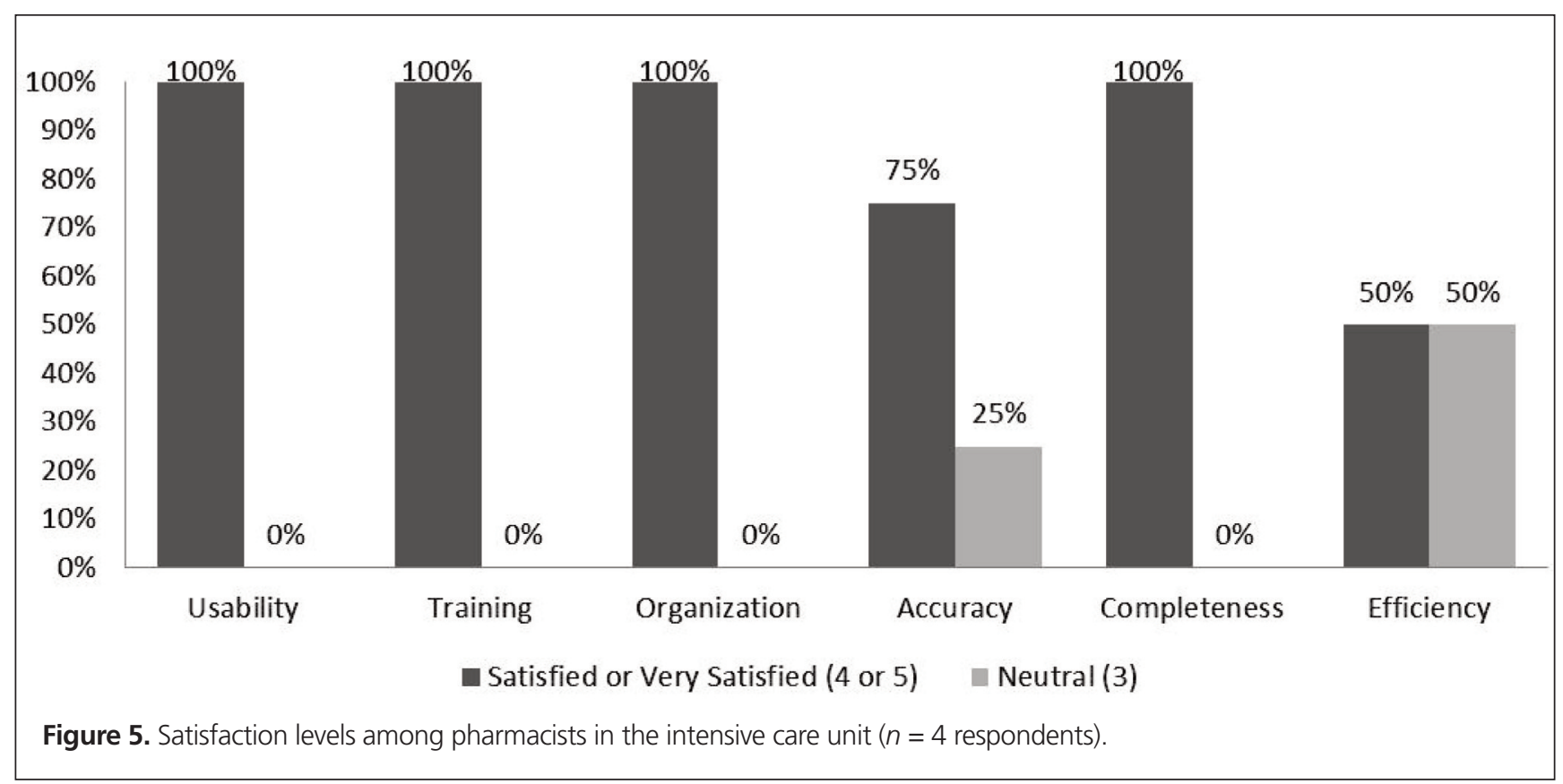




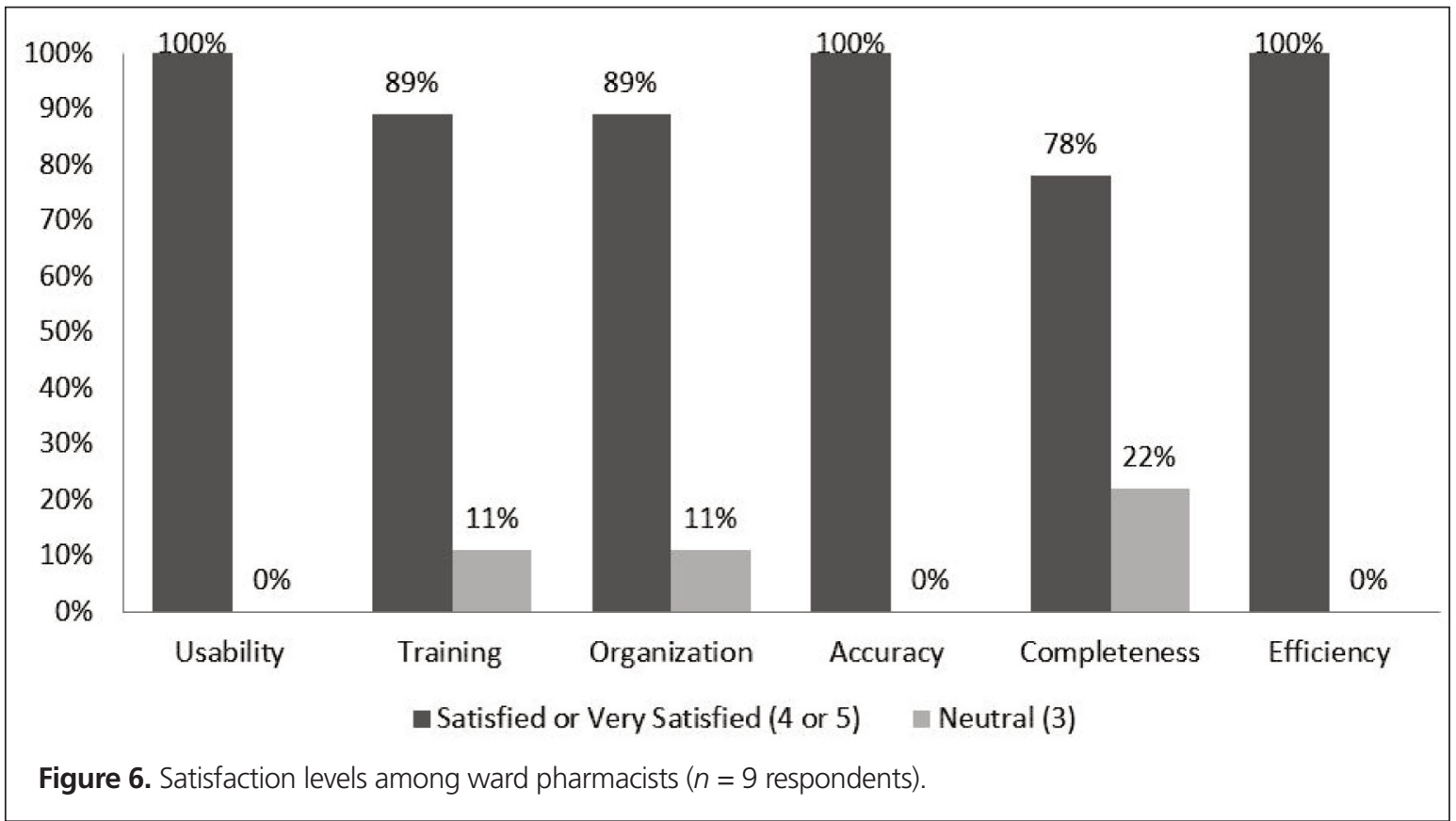

and $10(77 \%)$ of the pharmacists reported performing 1 or 2 handovers per week. The maximum workload reported was 5 handovers per week, up to $10 \mathrm{~min}$ in duration.

Communication outcomes are presented in Table 2. With respect to communication methods actually used, 7 (54\%) of respondents reported mostly or only using the phone, and $6(46 \%)$ reported mostly or only using face-to-face communication. In terms of preferences, 6 (46\%) of the respondents preferred face-to-face handover, and 3 (23\%) preferred handover by phone.

\section{DISCUSSION}

This study evaluated satisfaction with various aspects of a pharmacist-developed, pharmacotherapy-specific tool and process for clinical handover within a Canadian health authority. Overall, the study participants were satisfied with the handover tool and process that they helped to create. Participants were unanimously satisfied with the ease of using the tool. The efficiency domain had a lower overall satisfaction level, a result driven by lower satisfaction among ICU pharmacists. This finding may reflect several factors: handover likely causes disruption in workflow, the workload burden for handover falls mostly on ICU pharmacists, and the handover process focuses on patients who are near or have completed ICU discharge and potentially are a lower priority for the ICU pharmacists. Conversely, ward pharmacists were completely satisfied with efficiency, probably because the handover serves as a helpful head start toward the workup of a new patient. Completeness was another domain with a lower overall satisfaction level, a result driven by lower satisfaction among ward pharmacists. This finding may reflect the fact that, during handover, ward pharmacists are receiving specific
Table 1. Workload-Related Outcomes

\begin{tabular}{lrr} 
Outcome* & $\begin{array}{r}\text { No. (\%) of Respondents } \\
(\boldsymbol{n}=\mathbf{1 3})\end{array}$ \\
\hline Time to conduct handover & 1 & $(8)$ \\
$\leq 2 \mathrm{~min}$ & 8 & $(62)$ \\
$3-5 \mathrm{~min}$ & 4 & $(31)$ \\
$5-10 \mathrm{~min}$ & 0 & $(0)$ \\
$>10 \mathrm{~min}$ & & \\
\hline No. of handovers/week & 10 & $(77)$ \\
$\leq 2$ & 3 & $(23)$ \\
$3-5$ & 0 & $(0)$ \\
$5-10$ & 0 & $(0)$ \\
$>10$ & \multicolumn{3}{c}{}
\end{tabular}

information about drug-related issues without the luxury of much background information about the patient, which may give the impression of incomplete information transfer. Information available in medical records would be expected to provide context and fill in any information gaps. It is also understandable that ICU pharmacists perceived greater completeness and organization than their ward counterparts, given their familiarity with the patients and the information being provided. ICU pharmacists were also less satisfied than ward pharmacists with accuracy of the tool and process, which may be partly because they are not always present at patient discharge, and are therefore unaware of changes that may occur during or after patient transfer.

Utilization measures showed that workload requirements were minimal and that broad implementation across a regional health authority was achievable. Interestingly, face-to-face and phone handover were both well-used methods of communication, 
This single copy is for your personal, non-commercial use only.

For permission to reprint multiple copies or to order presentation-ready copies for distribution, contact CHHP at publications@cshp.ca

Table 2. Communication-Related Outcomes

\begin{tabular}{lccc} 
& \multicolumn{4}{c}{ Group; No. (\%) of Respondents } \\
\cline { 2 - 4 } Communication Mode & $\begin{array}{c}\text { All Pharmacists } \\
(\boldsymbol{n}=\mathbf{1 3 )}\end{array}$ & $\begin{array}{c}\text { ICU Pharmacists } \\
(\boldsymbol{n}=\mathbf{4})\end{array}$ & $\begin{array}{c}\text { Ward Pharmacists } \\
(\boldsymbol{n}=\mathbf{9})\end{array}$ \\
\hline Used & $5(38)$ & $2(50)$ & $3(33)$ \\
Face-to-face only & $1(8)$ & $0(0)$ & $1(11)$ \\
Mostly face-to-face & $4(31)$ & $1(25)$ & $3(33)$ \\
Phone only & $3(23)$ & $1(25)$ & $2(22)$ \\
Mostly phone & $0(0)$ & $0(0)$ & $0(0)$ \\
Both phone and face-to-face equally & $6(46)$ & $3(75)$ & $3(33)$ \\
Preferred & $3(23)$ & $1(25)$ & $2(22)$ \\
Face-to-face & $4(31)$ & $0(0)$ & $4(44)$ \\
Phone & & & \\
Both phone and face-to-face equally & & 0 &
\end{tabular}

but face-to-face interaction was preferred. These results suggest that the intricacies and clarity of face-to-face interaction may allow for a better handover experience, and that the convenience of phone communication could be reserved for when face-to-face communication is not possible because of time or location restraints.

One risk with verbal handover is a loss of information through reliance on memory. In one study comparing handover methods, there was information retention of $2.5 \%$ with verbalonly communication, $85.5 \%$ with verbal communication plus note-taking by the receiver, and $99 \%$ with use of a preprinted sheet containing all patient information. ${ }^{11}$ Therefore, it is important to stress the necessity of note-taking during handover. Incorporating a written component into the tool was not deemed feasible because of the potential for such a requirement to compromise efficiency and be a significant barrier to the ICU pharmacist's ability to incorporate handover into their daily practice. It might be argued that most information required to develop a care plan is already being documented, and that what is missing is the verbal communication of information not included in the documentation. Verbal interaction also provides opportunity for questions, discussion, collegiality, and peer-topeer education.

One strength of this study was the use of PDSA methodology. This approach allowed for adaptation to the real-world practice environment and adjustments for unforeseen difficulties, ensuring that the final version of the handover tool and process was fit-forpurpose. In addition, PDSA mitigated one possible barrier to the adoption of the tool, that is, the potential lack of insight among pharmacists regarding the need to change handover practices. Buy-in from the pharmacists was promoted through early engagement in the planning phase, which thereby avoided the risk of participants developing a negative bias toward using a tool that lacked their input. Additionally, much thought was put into arranging the checklist components of the tool in a manner that would flow logically and facilitate a narrative. Including narrative thought means that not only are specific pieces of information conveyed, but also the way in which those details fit together into a "story" that is unique to each patient, thereby making sense of patients' often complex and evolving clinical courses.

The limitations of this study included its small sample size, which may not be representative of clinical pharmacists practising in other regions of Canada or in other countries. It is acknowledged that many potential biases could not be practically measured or controlled for in the analysis. There was a risk of proficiency bias, whereby pharmacists naturally became more skilled at handover over the course of the intervention and thus might have developed a positive bias toward the outcomes of interest. Also, a risk of responder bias exists, because the pharmacists who participated in development of the handover tool and process also participated in the evaluation. The pharmacists self-reported utilization measures, so there was a risk of recall bias. As well, a risk of researcher bias exists, in that the survey questionnaire may have posed questions in a manner leading toward positive responses. Finally, although study participants were satisfied with the tool, such satisfaction does not necessarily translate into improvements in clinical outcomes. Further study and evaluation will be required to address the impacts of this handover tool and process on process and outcome measures.

Development of and evaluation of satisfaction with a pharmacist-specific clinical handover tool and process align with many national and global handover initiatives. Shifting from an "individual-dependent" process to a standardized process for patient transfer has been endorsed internationally. ${ }^{12,13}$ In North America, Accreditation Canada's 2017 Required Organizational Practices have mandated that "the [health care] team transfers information effectively among service providers at transition points". ${ }^{14}$ This new tool and process represent a mechanism for information transfer that has the potential to enhance the consistency, efficiency, efficacy, and safety of patient care.

Given the crucial role of ICU pharmacists in providing care to patients in the ICU, appropriate handover processes are needed to ensure that each patient's drug therapy needs are met while in hospital after leaving the ICU, and such processes may prevent 
unfavourable consequences for patients, families, practitioners, and the health care system. It is important to emphasize that although medication reconciliation at transitions is an essential part of the tool and process created here, their ultimate purpose was to meet the priority pharmacotherapy needs of patients during and after the transfer of care.

A PubMed search from inception to March 1, 2017, showed no published literature on handovers from ICU pharmacists to ward pharmacists for comparison. Therefore, further research on the subject is necessary, specifically to determine impacts on information transfer, processes of care such as DTP resolution rates, and outcomes such as medication adherence rates. Moreover, future evaluation is needed to address the potential impacts of this standardized handover tool and process on patients being transferred into the ICU from other areas of the hospital.

\section{CONCLUSION}

Pharmacists participating in this survey study were satisfied with the systematic development and implementation of a pharmacist-specific clinical handover tool and process. This tool and process have the potential to improve information transfer, which may in turn improve processes of care and outcomes.

\section{References}

1. Rudis MI, Brandl KM; Society of Critical Care Medicine and American College of Clinical Pharmacy Task Force on Critical Care Pharmacy Services. Position paper on critical care pharmacy services. Crit Care Med. 2000; 28(11):3746-50.

2. Chant C. How critical are critical care pharmacists? [editorial]. Can J Hosp Pharm. 2012;65(1):5-6.

3. Riesenberg LA. Shift-to-shift handoff research: where do we go from here? J Grad Med Educ. 2012 [cited 2017 Mar 27];4(1):4-8. Available from: https://www.ncbi.nlm.nih.gov/pmc/articles/PMC3312531/

4. Solet DJ, Norvell JM, Rutan GH, Frankel RM. Lost in translation: challenges and opportunities in physician-to-physician communication during patient handoffs. Acad Med. 2005;80(12):1094-9.

5. Sentinel event data: root causes by event type 2004-2014. Oakbrook Terrace (IL): The Joint Commission, Office of Quality and Patient Safety; 2014 [cited $2018 \mathrm{Mar}$ 27]. Available from: www.tsigconsulting.com/tolcam/ wp-content/uploads/2015/04/TJC-Sentinel-Event-Root_Causes_by_ Event_Type_2004-2014.pdf

6. Coutsouvelis J, Corallo CE, Dooley MJ, Foo J, Whitfield A. Implementation of a pharmacist-initiated pharmaceutical handover for oncology and haematology patients being transferred to critical care units. Support Care Cancer. 2010;18(7):811-6.

7. Zimmerman JE, Kramer AA, McNair DS, Malila FM, Shaffer VL. Intensive care unit length of stay: benchmarking based on Acute Physiology and Chronic Health Evaluation (APACHE) IV. Crit Care Med. 2006;34(10): 2517-29.
8. Gagnon MP, Desmartis M, Labrecque M, Car J, Pagliari C, Pluye P, et al. Systematic review of factors influencing the adoption of information and communication technologies by healthcare professionals. J Med Syst. 2012; 36(1):241-77.

9. How to improve. Boston (MA): Institute for Healthcare Improvement; 2017 [cited 2017 Mar 10]. Available from: www.ihi.org/resources/Pages/ HowtoImprove/default.aspx

10. World Health Organization Collaborating Centre for Patient Safety Solutions. Communication during patient hand-overs. Patient Saf Solut. 2007;1(3). Available from: www.who.int/patientsafety/solutions/patientsafety/PSSolution3.pdf

11. Bhabra G, Mackeith S, Monteiro P, Pothier D. An experimental comparison of handover methods. Ann R Coll Surg Engl. 2007;89(3):298-300.

12. Safe handover: safe patients. Guidance on clinical handover for clinicians and managers. London: British Medical Association; 2004.

13. OSSIE guide to clinical handover improvement. Sydney (Australia): Australian Commission on Safety and Quality in Health Care; 2010 [cited 29 Jul 2015]. Available from: www.safetyandquality.gov.au/wp-content/uploads/2012/01/ ossie.pdf

14. Required organizational practices handbook 2017. Ottawa (ON): Accreditation Canada; 2017 [cited 2018 Mar 27]. Electronic version accessed through institutional resources.

Emma Attfield, BSC(Pharm), ACPR, is with Fraser Health Pharmacy Services, Surrey, British Columbia.

Matthew P Swankhuizen, BSC(Pharm), PharmD, is with Kootenay Boundary Regional Hospital, Interior Health Pharmacy Services, Trail, British Columbia, and the Faculty of Medicine, The University of British Columbia, Vancouver, British Columbia.

Nicole Bruchet, BSC, BSc(Pharm), ACPR, PharmD, is with Kelowna General Hospital, Interior Health Pharmacy Services, Kelowna, British Columbia, and the Faculty of Pharmaceutical Sciences, The University of British Columbia, Vancouver, British Columbia.

Richard Slavik, BSC(Pharm), ACPR, PharmD, FCSHP, is with Interior Health Pharmacy Services, Kelowna, British Columbia, and the Faculty of Pharmaceutical Sciences, The University of British Columbia, Vancouver, British Columbia.

Sean K Gorman, BSC (Pharm), ACPR, PharmD, is with Interior Health Pharmacy Services, Kelowna, British Columbia, and the Faculty of Pharmaceutical Sciences, The University of British Columbia, Vancouver, British Columbia.

Competing interests: None declared.

\section{Address correspondence to:}

Matthew P Swankhuizen

Interior Health Pharmacy Services

1200 Hospital Bench

Trail BC V1R 4M1

e-mail: matthew.swankhuizen@interiorhealth.ca

Funding: None received. 